\title{
CHARACTERIZATION OF NANOMETRIC-SIZED CARBIDES FORMED DURING TEMPERING OF CARBIDE-STEEL CERMETS
}

\begin{abstract}
The aim of this article of this paper is to present issues related to characterization of nanometric-sized carbides, nitrides and/or carbonitrides formed during tempering of carbide-steel cermets. Closer examination of those materials is important because of hardness growth of carbide-steel cermet after tempering. The results obtained during research show that the upswing of hardness is significantly higher than for high-speed steels. Another interesting fact is the displacement of secondary hardness effect observed for this material to a higher tempering temperature range. Determined influence of the atmosphere in the sintering process on precipitations formed during tempering of carbide-steel cermets. So far examination of carbidesteel cermet produced by powder injection moulding was carried out mainly in the scanning electron microscope. A proper description of nanosized particles is both important and difficult as achievements of nanoscience and nanotechnology confirm the significant influence of nanocrystalline particles on material properties even if its mass fraction is undetectable by standard methods. The following research studies have been carried out using transmission electron microscopy, mainly selected area electron diffraction and energy dispersive spectroscopy. The obtained results and computer simulations comparison were made.

Keywords: Carbide-steel cermet; HRTEM; STEM; Tempering
\end{abstract}

\section{Introduction}

Carbide-steel cermets manufactured with the Powder Injection Moulding (PIM) method is a prospective tool material. Interesting properties of materials obtained by PIM results from high mechanical properties, unlimited possibility to select its chemical composition and because of the ability to obtain pieces with a high shape complexity. In tool materials processing, PIM method is enjoying the special attention as it makes possible to form small elements with high surface area, not possible to obtain by conventional powder pressing. In order to correctly describe nanosized carbides and nitrides, it was necessary to apply techniques offering a nanometric resolution. So far examination of carbide-steel cermet produced by powder injection moulding was carried out mainly in the scanning electron microscope. The purpose of this article is to examine the precipitated carbides using techniques available in transmission electron microscopy [1-6].

\section{2. Experimental procedure}

The investigation was performed on the two materials: high-speed steel HS6-5-2 and carbide-steel cermet based on HS6-5-2 improved with a mixture of carbides. Second material was formed by a powder injection moulding process using HS6-5-2 steel powder (chemical composition is shown in Table 1) and a commercial mixture of tungsten (WC), titanium $(\mathrm{TiC})$, niobium $(\mathrm{NbC})$ and tantalum $(\mathrm{TaC})$ carbides (respectively: 33.3 / 33.3 / 26.6 / 6.8\%). HS6-5-2 steel powder had an average particle size of about $16 \mu \mathrm{m}$. Carbide particle size was smaller and was about $1.5 \mu \mathrm{m}$. The mixture of polypropylene and paraffin wax was used as a binder for the moulding process. After the moulding process, the resulting material was subjected to the degradation of the binder. This step was important because, during heating to the sintering temperature, the polymer contained in the binder is gasified. The gas pressure contained within the pores is increasing and it is possible to damage the sample. The sample was then sintered to provide the appropriate shape and permanent connection of the powder particles. After that the sample was heat treated in order to improve the mechanical properties.

TABLE 1

The chemical composition of high-speed steel HS6-5-2 powder mass fraction of element [\%]

\begin{tabular}{|c|c|c|c|c|c|c|c|}
\hline \hline \multicolumn{7}{|c|}{ Mass fraction of element [\%] } \\
\hline $\mathrm{C}$ & $\mathrm{Mn}$ & $\mathrm{Si}$ & $\mathrm{Cr}$ & $\mathrm{W}$ & $\mathrm{Mo}$ & $\mathrm{V}$ & $\mathrm{Co}$ \\
\hline $\begin{array}{c}0.82- \\
0.92\end{array}$ & $<0.4$ & $<0.5$ & $\begin{array}{c}3.5- \\
4.5\end{array}$ & $6-7$ & $\begin{array}{c}4.5- \\
5.5\end{array}$ & $\begin{array}{c}1.7- \\
2.1\end{array}$ & $<0.5$ \\
\hline
\end{tabular}

Two samples shown in Table 2 were used for this study. Steel sample (indicated as HSS 6-5-2) was produced by the powder injection moulding and sintered at $1285{ }^{\circ} \mathrm{C}$ in a reducing atmosphere $\mathrm{N} 2-10 \% \mathrm{H} 2$. The second sample was carbide-steel cermet made from a combination of high-speed steel HS-6-5-2 (the chemical composition set out in Table 1) with "tetra carbides". This material was manufactured by powder injection moulding. The sample was sintered at $1260^{\circ} \mathrm{C}$

* SILESIAN UNIVERSITY OF TECHNOLOGY, INSTITUTE OF ENGINEERING MATERIALS AND BIOMATERIALS, FACULTY OF MECHANICAL ENGINEERING, 18A KONARSKIEGO STR., 44-100 GLIWICE, POLAND

\# Corresponding author: krzysztof.matus@polsl.pl 
in a reducing atmosphere $\mathrm{N} 2-10 \% \mathrm{H} 2$, and then hardened at sintering temperature and tempered twice at $630^{\circ} \mathrm{C}$.

TABLE 2

The basic parameters of the samples used in tests

\begin{tabular}{|c|c|c|c|c|}
\hline \hline No. & Material & $\begin{array}{c}\text { Sintering } \\
\text { temperature }\end{array}$ & $\begin{array}{c}\text { Sintering } \\
\text { atmosphere }\end{array}$ & Treatment \\
\hline 1 & HS6-5-2 & $1285^{\circ} \mathrm{C}$ & $\mathrm{N}_{2}-10 \% \mathrm{H}_{2}$ & - \\
\hline 2 & $\begin{array}{c}\mathrm{HS} 6-5-2+\text { tetra } \\
\text { carbides }\end{array}$ & $1260^{\circ} \mathrm{C}$ & $\mathrm{N}_{2}-10 \% \mathrm{H}_{2}$ & $1)$ \\
\hline \multicolumn{4}{|c|}{ 1) Hardening from sintering temperature and subsequent double } \\
tempering at $630^{\circ} \mathrm{C}$
\end{tabular}

Both samples after cutting were dissolved in concentrated hydrochloric acid $\mathrm{HCl}$ in order to extract carbides and dissolve the matrix. This procedure was necessary for proper investigation of the nanometer size precipitates and to reduce the impact of the matrix on the achieved results. Samples for transmission electron microscopy were prepared by dispersing powder in ethanol, placing in an ultrasonic bath, then putting droplets onto $3 \mathrm{~mm}$ copper grids coated with amorphous carbon film and drying in air at room temperature. The study was carried in transmission electron microscope S/TEM Titan 80300. Scanning transmission electron microscope (STEM) and HRTEM (High Resolution Transmission Electron Microscopy) imaging were used as primary research techniques. The diffraction patterns were collected by exploiting both Selected Area Diffraction (SEAD) and Fourier transformations from HRTEM images. Chemical composition examinations were carried out by energy dispersive spectrometry (EDS). This made possible to identify precipitates that occurred in the sample. To supplement the results, additional research were performed using a scanning electron microscope.

\section{Results}

A representative SEM image of carbides extracted from carbide-steel cermets is presented in Fig. 1. Two kinds of precipitates can be here distinguished. The first one are polyhedrons, about 1 micron in size. They are surrounded by smaller (below $100 \mathrm{~nm}$ ), spherical ones. In order to examine smaller precipitates TEM imaging have to be applied. A HAADF image of selected carbonitrides from steel sample (HS6-5-2) is present in the Fig. 2a. Their chemical composition was confirmed by EDS measurements (Fig. 2b and Fig. 2c). The shapes of these carbonitrides are generally spherical, and the size does not exceed $1 \mu \mathrm{m}$. HRTEM image of selected precipitate is presented in Fig. 3. Distances obtained from SAED pattern (inset in Fig. 3) were compared with the JCPDS Card number 35-0786. Taking into consideration the results of chemical composition, it allows to identify precipitates as vanadium carbonitride MX (computer simulation of the unit cell is presented in Figure 4).

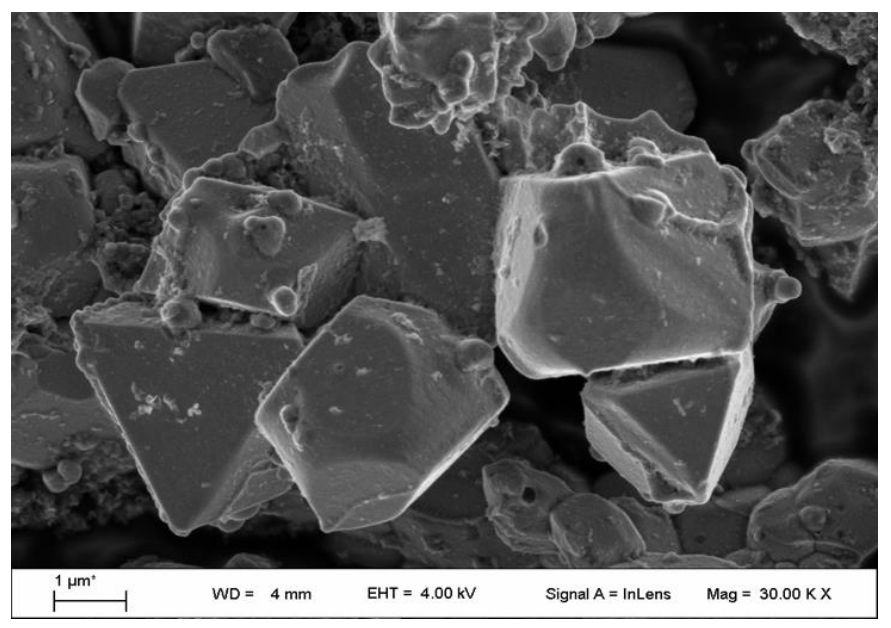

Fig. 1. SEM image of carbides extracted by dissolving the metal matrix with acid

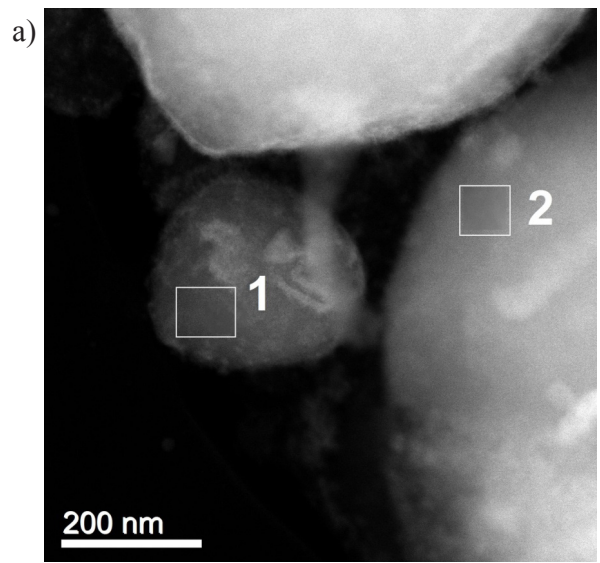

b)
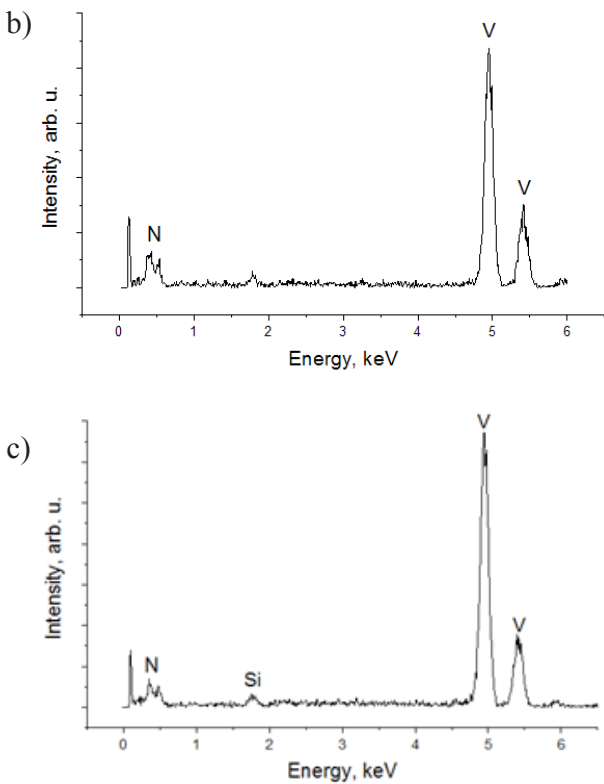

Fig. 2. a) HAADF image of selected carbonitrides from steel sample (HS6-5-2), b) EDS spectrum from the first area, c) EDS spectrum from the second area 


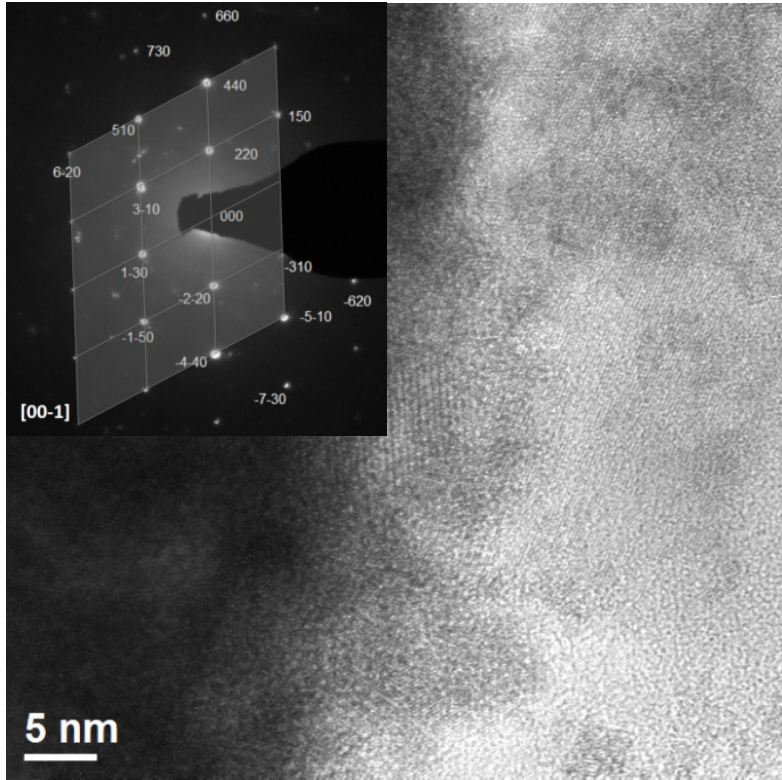

Fig. 3. HRTEM image of selected carbonitride from steel sample (the first area in the Fig. 2a). The corresponding SAED pattern was taken from the same place

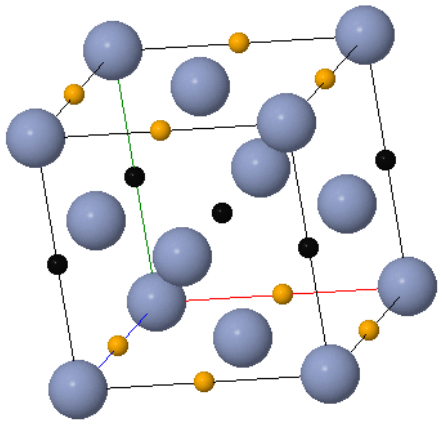

Fig. 4. Computer simulation of unit cell of vanadium carbonitride MX

Vanadium carbonitride MX is very similar to vanadium carbide, the difference is the replacement of part of the carbon atoms by nitrogen atoms. The carbon atoms occupy the octahedral positions in the gaps between the vanadium atoms, nitrogen atoms occupy the position of the carbon atoms at random. The unit cell parameters are (space group Fm3m), $\mathrm{a}=4.182 \mathrm{~A} \alpha=90^{\circ}$ (Fig. 4).

Figure 5a presents HAADF image of the same precipitate, the chemical analysis result is shown in Fig. 5b. Figure 6 presents HRTEM pictures of chosen area from Fig. 5a. The observed precipitate is polycrystalline, and the average subgrain size is about $6 \mathrm{~nm}$. Interplanar distances determined from FFT (Fig. 7), compared with JCPDS Card number 23-1127, as well as EDS results allowed to identify this precipitation as $\mathrm{M} 6 \mathrm{C}$ carbide, computer simulation of the unit cell is presented in Figure 8 .
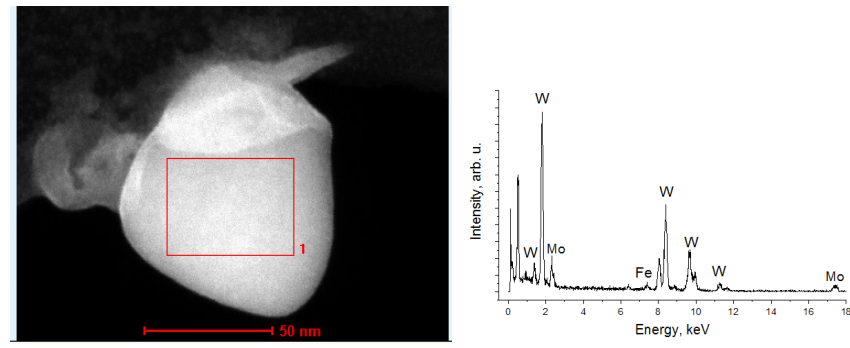

Fig. 5. a) HAADF image of precipitate in carbide-steel cermet sample (HS6-5-2 + tetra carbides), b) EDS spectrum of precipitate in carbidesteel cermet

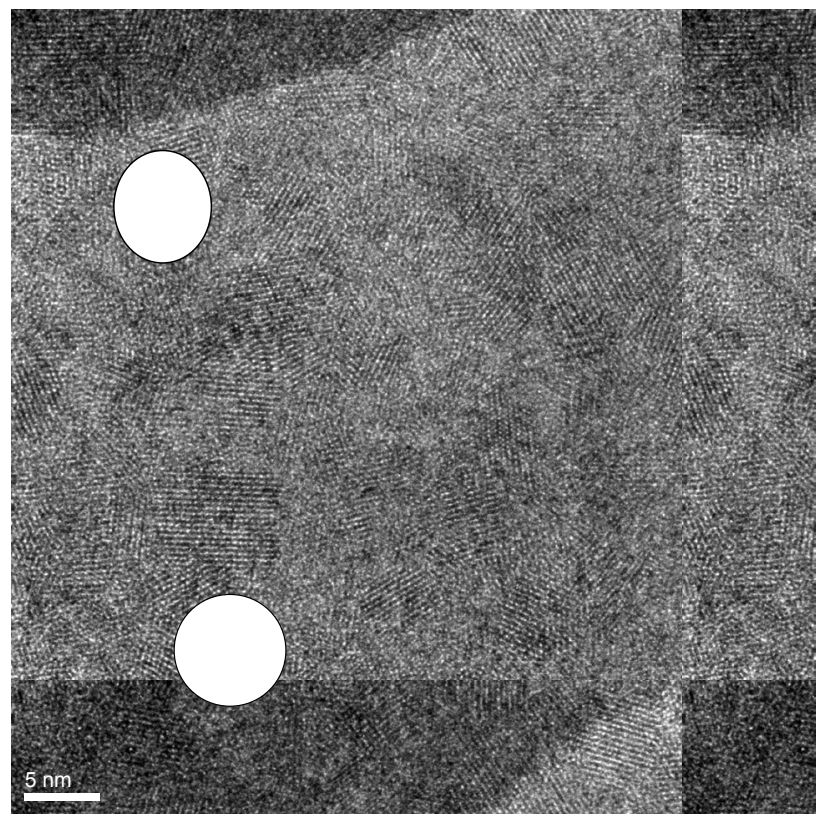

Fig. 6. HRTEM image of precipitate in carbide-steel cermet sample (HS6-5-2 + tetra carbides), yellow circles represents subgrains (ordered domains)

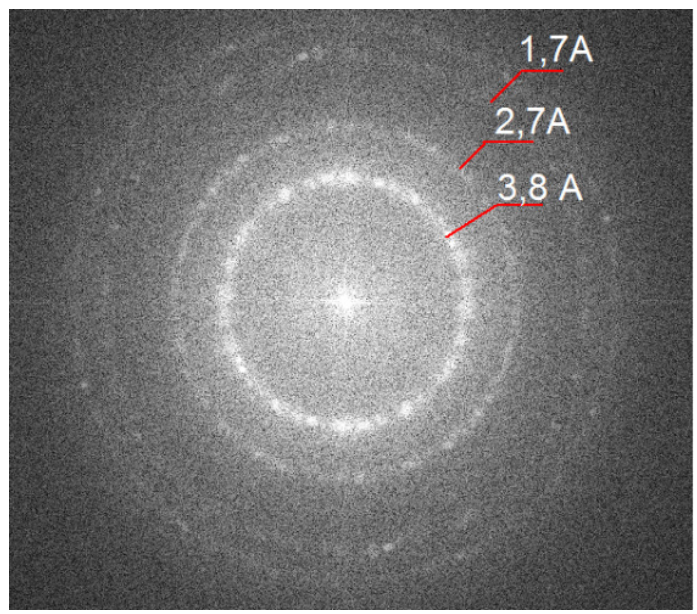

Fig. 7. FFT of HRTEM image (Fig. 6) of precipitate in carbide-steel cermet sample (HS6-5-2 + tetra carbides) 


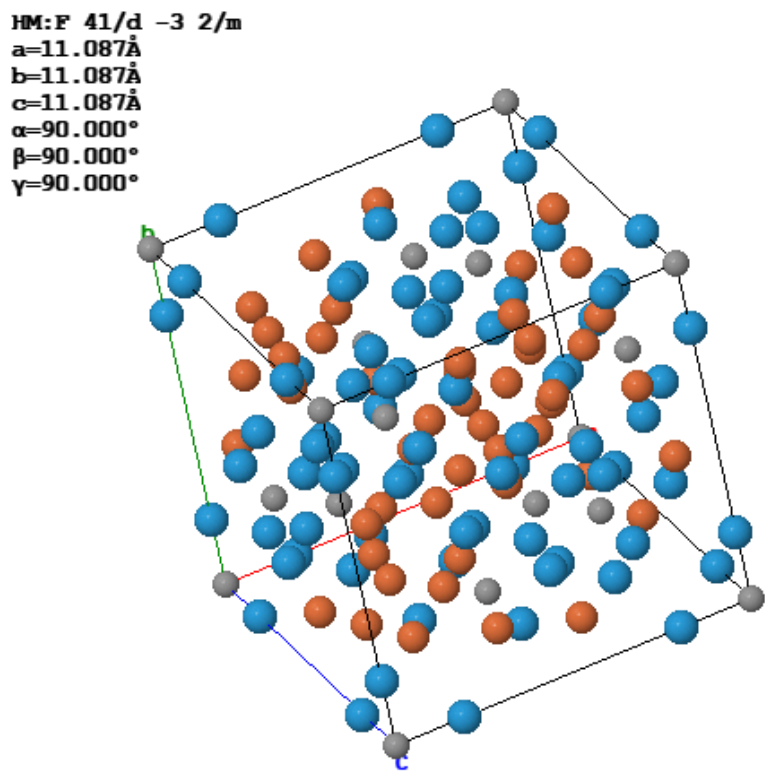

Fig. 8. Computer simulation of the unit cell of M6C

Complex carbide M6C has a very complicated crystallographic structure (Fig. 8), its structure includes 96 atoms of metals and 16 carbon atoms. Carbide of this type is a complex carbide which mean it always consists with atoms of at least two metallic elements. The simplest type carbide that is present in the steels is $\mathrm{Fe} 3 \mathrm{~W} 3 \mathrm{C}$. Iron atoms occupy a privileged position, and the tungsten atom in a position in the tetrahedral gaps, which makes them less stable. Therefore, in the case of the above steel alloys, in which the chemical composition has other carbide forming elements, some tungsten For the most M6C carbide of tungsten are present in addition to the atoms of molybdenum, so popular description of this carbide as $\mathrm{Fe} 3(\mathrm{~W}, \mathrm{Mo}) 3 \mathrm{C}$. Space group number of this carbide is 227 (Fd-3m), $\mathrm{a}=11.084 \mathrm{~A} \alpha=90^{\circ}$ (Fig. 8).

Figure 9 presents the HAADF-STEM image of vanadium carbides added to steel and not dissolved in the metal matrix during sintering and tempering. Vanadium carbide can be recognized by the shape and size, as well as by SAED pattern (comparison with JCPDS Card number 65-3772, Fig. 10). Computer simulation of the unit cell is presented in Figure 11.

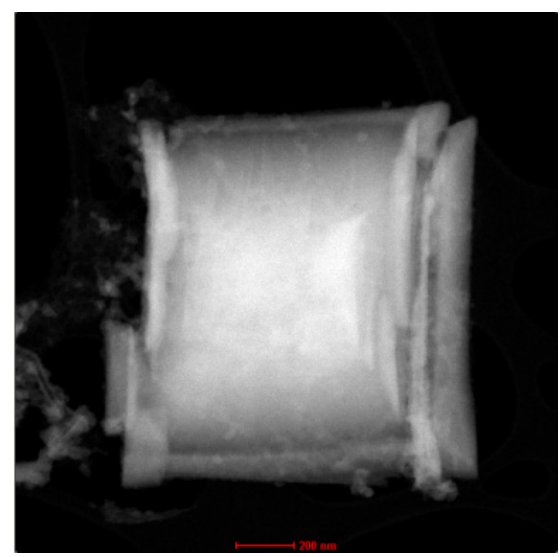

Fig. 9. HAADF-STEM image of vanadium carbide

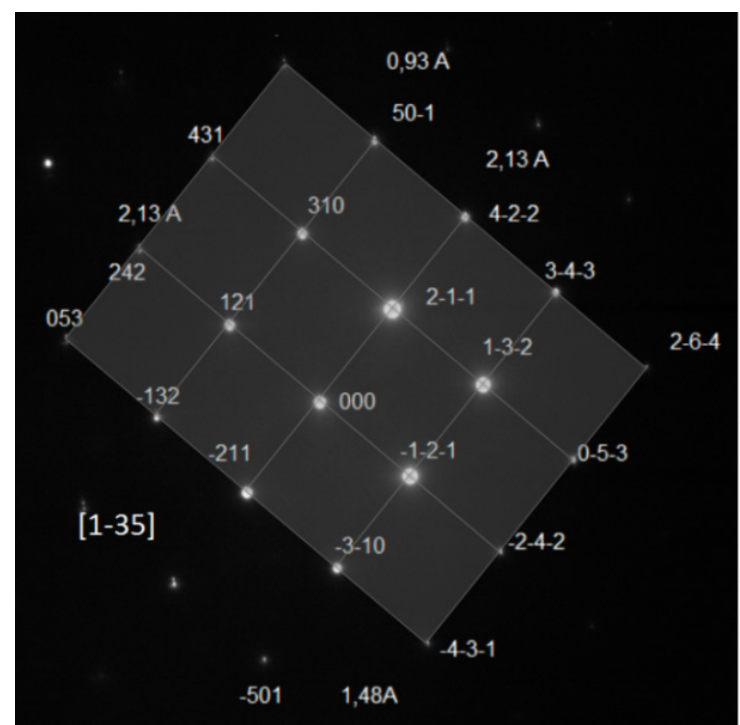

Fig. 10. SAED pattern taken from vanadium carbide in Fig. 8

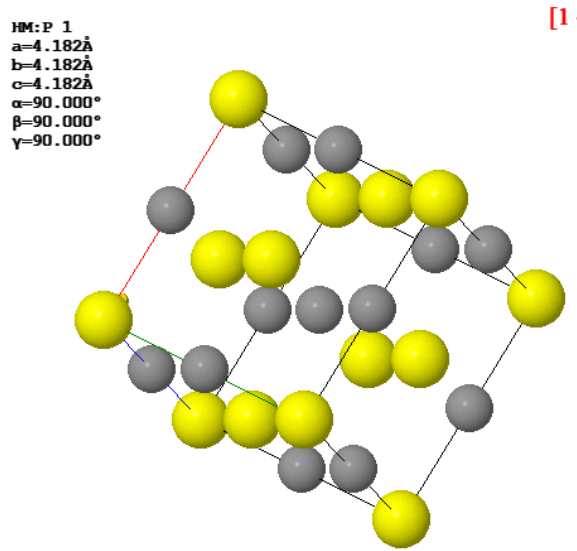

Fig. 11. Simulation of the unit cell of vanadium carbide in the direction [1-35]

\section{Discussion}

Application of high resolution transmission electron microscope for carbide-steel cermet and high-speed steels produced by powder injection moulding studies allows for a more detailed investigation of these tool materials' structure. In particular, the carbide precipitations were examined for double tempered carbide-steel cermet. In the literature, the usage of a high resolution transmission microscopy for precipitates identification for similar materials is rarely seen. This is most often carried out by scanning electron microscopy with EDX add-on, enabling the study of the chemical composition of precipitates, which does not allow for an unambiguous determination of the resulting precipitates. In order to accurately determine the type of precipitates occurring in the studied materials diffraction methods should be used. In this case, high-resolution transmission microscope appears to be a necessary tool for identification of hard carbide phases which size is often smaller than $100 \mathrm{~nm}$. In addition, EDX adapter allows for analysis of chemical composition with 
better resolution than the scanning microscopes. TEM studies enabled the researchers to determine the types of precipitates formed in injection moulded high-speed steels and carbidesteel cermet during the process of sintering and heat treatment. Application of protective atmosphere rich in nitrogen results in precipitation of carbonitrides MX rich in vanadium in the case of high-speed steel, while for carbide-steel cermet the carbonitrides were rich in vanadium, titanium, and tantalum. Carbides of $\mathrm{Ti}$ and $\mathrm{Ta}$ present as a dopant in carbide-steel cermet dissolved and secreted in the form of a complex carbonitride for which a large amount of vanadium is coming from high-speed steel. There was no occurrence of tungsten carbide in MX carbonitrides, which proves its complete dissolution and precipitation in the form of M6C. There was clearly no occurrence of nitrogen in these phases. Therefore, it can be assumed that the phase M6X did not emerge during sintering in an atmosphere rich in nitrogen. Also, it is difficult to determine whether the phase M6C visible in Figure 6 and 7 is formed during tempering. This can only be confirmed by examining thin films and resolving dependencies between precipitates and crystallographic martensitic matrix. HRTEM analysis and FFT images revealed that the precipitation is polycrystalline, and the average grain size was about $6 \mathrm{~nm}$.

\section{Conclusions}

1. Tool materials produced by powder injection moulding in the form of high-speed steel and carbide-steel cermet are characterised by fine carbide precipitates and carbonitrides not exceeding 1 micron in size, irrespectively of the sintering conditions.

2. Resolved diffraction helped to identify carbides precipitations as $\mathrm{V} 8 \mathrm{C} 7$ and $\mathrm{Fe} 3 \mathrm{~W} 3 \mathrm{C}$, but high nitrogen content, confirmed by analysis of chemical composition, leads to the conclusion that these precipitations are carbonitrides $\mathrm{MX}$ and $\mathrm{M} 6 \mathrm{C}$ carbides. These results are consistent with literature data.

3. WC, $\mathrm{TiC}, \mathrm{TaC}$ and $\mathrm{NbC}$ carbides introduced into HSS dissolve at high temperature sintering of $1260^{\circ} \mathrm{C}$ and were secreted in the form of MX carbonitrides. In these phases, there was no tungsten, which is secreted independently of the sintering atmosphere in $\mathrm{M} 6 \mathrm{C}$ carbides with the addition of Mo.
4. Precipitations of MX carbonitrides is a typical phenomenon due to the high affinity of nitrogen to elements constituting the cubic MC phase, like V, Ti, Ta, $\mathrm{Nb}$. This is caused by smaller diameter ratio of nitrogen atoms to carbon.

5. Complete studies have shown that carbonitrides created in the process of tempering may be characterised by a nanometric size. In analysed carbide-steel cermet the carbonitride shown in Fig. 6 has a structure of fine subgrain of size about $6 \mathrm{~nm}$. This may be due to the coagulation of the dispersion of carbides secreted from martensite, which is difficult to prove without applying thin films examination.

\section{Acknowledgements}

This publication was financed by the Ministry of Science and Higher Education of Poland as the statutory financial grant of the Faculty of Mechanical Engineering SUT.

\section{REFERENCES}

[1] G. Matula, L.A. Dobrzański, A. Várez, B. Levenfeld, J.M. Torralba, J Mater Process Tech. 162, 230-235 (2005).

[2] M. Bonek, G. Matula, L.A. Dobrzański, Adv Mat Res. 291294, 1365-1268 (2011).

[3] L.A. Dobrzański, D. Pakuła, J. Mikuła, K. Gołombek, Int. J Surf Sci Eng, 1, (1), 111-124 (2007).

[4] P. Echlin, Springer, Handbook of sample preparation for scanning electron microscopy and $\mathrm{x}$-ray microanalysis, New York 2009.

[5] L.A. Dobrzański , K. Gołombek, J Mater Process Tech, 164165, 805-815 (2005).

[6] S. Kuimalee, T. Chairuangsri, J.T.H. Pearce, D.V. Edmonds, A.P. Brown, R.M.D. Brydson, Micron 41, (5), 423-429 (2010).

[7] P.W. Hawkes, J.C.H Spence, Springer, Science of microscopy, New York 2007.

[8] J.A. Pérez-Omil. PhD thesis, University of Cadiz-Spain (1994).

[9] S. Bernal, F.J. Botana, J.J. Calvino, C. Lopez-Cartes, J.A. Perez-Omil, J.M. Rodriguez-Izquierdo. Ultramicroscopy 72, 135-164 (1998). 
